\title{
Linear accelerator-based stereotactic body radiation therapy in the treatment of oligometastatic disease
}

\author{
HIDEOMI YAMASHITA, MAMI OGITA, SHURI AOKI, OSAMU ABE and KEIICHI NAKAGAWA \\ Department of Radiology, University of Tokyo Hospital, Tokyo 113-8656, Japan
}

Received July 10, 2018; Accepted October 11, 2019

DOI: $10.3892 / \mathrm{mco} .2020 .2065$

\begin{abstract}
The present study reports the clinical outcomes of hypofractionated stereotactic body radiation therapy (SBRT) for oligometastasis (OM) originating from various tumors. Between February 2012 and April 2017, 40 patients with unresectable OM were treated with SBRT. Of these patients, 92\% showed a solitary nodal metastasis and the rest had up to three metastases. The dose prescription was 50 Gy in 10 fractions with three-dimensional conformal techniques or volumetric intensity-modulated arc therapy. Median follow-up was 14 months. Of the 40 patients, none showed local progression at the site of SBRT, but 20 patients showed tumor growth at distant sites during follow-up. The 2- and 3-year overall survival rates were 45.1 and $36.1 \%$, respectively. The 2- and 3-year progression-free survival rates were 35.4 and $26.5 \%$, respectively. The interval between diagnosis and detection of OM ( $<2$ vs. $>2$ years) and primary tumor site (esophagus vs. others) emerged as significant variables affecting survival. Grade 3 subacute and grade 4 chronic toxicities were observed in 1 and 2 patients, respectively. SBRT of 50 Gy in 10 fractions for OM from various primary tumors was shown to lead to good clinical outcomes from the viewpoints of local control and toxicity frequency. However, additional studies are required to identify the patient groups likely to receive maximal benefits from such treatment.
\end{abstract}

\section{Introduction}

By undertaking local treatment, such as surgical resection, radiation therapy or radiofrequency ablation, for a small number of recurrent or metastatic cancers for metastatic lesions, patient survival can be prolonged (1). Patients with oligometastasis (OM) follow a unique course and, according to previous reviews $(1,2)$, there is increasing evidence of improved prognosis for this condition. According to National

Correspondence to: Dr Hideomi Yamashita, Department of Radiology, University of Tokyo Hospital, 7-3-1 Hongo, Bunkyo-ku, Tokyo 113-8656, Japan

E-mail: yamachan07291973@yahoo.co.jp

Key words: recurrence, stereotactic body radiation therapy, stereotactic body radiotherapy, oligometastasis
Cancer Institute Dictionary (3), OM is a type of metastasis in which cancer cells from the original primary tumor travel through the body and form a small number of new metastatic tumors in one or more other parts of the body.

According to a review by Ashworth et al (1), local treatment, such as surgical resection or stereotactic body radiation therapy (SBRT), has emerged as an additional treatment for OM. Either surgical resection, chemoradiotherapy (CRT) or a tri-modality of surgery plus CRT is commonly selected as a curative treatment strategy $(4,5)$.

Depending on location, SBRT induces minimal side effects and exhibits long-lasting local control (2,6-8). However, there are limited data concerning the outcome and side effects following SBRT for metastasis. A study to investigate the safety, efficacy and toxicity of SBRT for OM is therefore required. Certain clinical data exist regarding the application of SBRT, with a protocol of 50 Gy delivered in 10 fractions for OM at various sites except for the brain (9-12). SBRT has also been used for OM in the abdominal lymph nodes (LNs) (5,13-16).

Although concurrent CRT has become the first method of choice for isolated LN metastasis after primary radical treatment for solid cancers, certain clinical cases exist for which the administration of chemotherapy is difficult, due to reasons such as having an unsatisfactory general condition, renal failure or being elderly, and in such cases, radiation therapy alone becomes a treatment option; however, the local control rate is inadequate when using conventional radiation therapy alone with 2 Gy for each fraction (5,8,10-15). Therefore, it is highly likely that SBRT using an increased radiation dose per fraction will be more useful due to the enhanced antitumor effect.

At our institution, in cases where the administration of chemotherapy was difficult on the basis of the cancer being inoperable for various reasons, including patients who refused surgery, or had decreased renal function or poor general condition, SBRT was performed for OM after primary radical treatment. The safety and effectiveness of SBRT in the treatment of OM from various cancers were examined in the present study.

\section{Materials and methods}

Study participants. A total of 40 patients were recruited in this retrospective cohort study (median age, 70 years; range, 51-91 years; 29 males and 11 females) at the University of Tokyo Hospital between February 2012 and April 2017. Ethical approval was granted by the Clinical Research Review Board 
of the University of Tokyo Hospital. Informed consent was obtained from all patients prior to the initiation of procedures.

The following inclusion criteria were set for the study: i) The maximum diameter of the $\mathrm{OM}$ was not more than $5 \mathrm{~cm}$; ii) up to three lesions per patient were present; iii) an increasing trend for computed tomography (CT) scanning was noted; iv) by positron emission tomography (PET) scanning, an accumulation of 2-(18F)fluoro-2-deoxy-D-glucose (FDG) with a maximum standardized uptake value (SUV-max) $\geq 2.0$ was present (15); v) the OM lesion was judged as inoperable by the respiratory cancer board; vi) there was no history of radiation therapy for the target lesion; vii) the Karnofsky performance status (KPS) (17) was $\geq 60 \%$; viii) the primary tumor was confirmed via pathology; and ix) the prognosis was expected to be $>3$ months.

Treatment. SBRT of a total of $50 \mathrm{~Gy}$ in 10 fractions was performed 5 times a week using a linear accelerator (linac). Adjuvant therapy was not acceptable soon after SBRT. However, additional treatment for relapse cases after SBRT was allowed. This treatment had been performed since February 2012, and those patients who received SBRT up to April 2017 were analyzed.

Irradiation method. Image-guided radiation therapy was performed each time. Each OM was contoured as separate irradiation sites. Four-dimensional (4D)-CT was used when possible.

The gross tumor volume (GTV) was for a tumor detectable via CT. The internal target volume (ITV) was calculated from the sum of all GTVs from 4D-CT. The margin between the ITV and clinical target volume (CTV) was $0 \mathrm{~mm}$. In other words, the microinvasive margin was not added. The margin between the CTV and the planning target volume (PTV) was $5 \mathrm{~mm}$ in all six directions. The stomach, duodenum, small intestine, liver, spinal cord and kidney were contoured as the organs at risk. The prescribed dose was calculated to cover $95 \%$ of PTV or the point of the isocenter using volumetric modulated arc therapy (VMAT). The total radiation dose was $50 \mathrm{~Gy}$ in 10 fractions over 2 weeks. The biologically effective dose (BED) in the $\alpha / \beta=10$ was 75 Gy.

Adverse events related to SBRT were evaluated using the National Cancer Institute Common Terminology Criteria for Adverse Events version 3.0 (18). The primary tumor at initial diagnosis was staged according to the sixth edition of the American Joint Committee on Cancer (19).

Follow-up schedule. Regarding the post-treatment follow-up schedule, neck, chest, abdominal and pelvic CT scans with contrast if possible were performed at intervals of 3-4 months for the first 3 years, and 4-6 months after this time point. Complete response was evaluated according to the Response Evaluation Criteria In Solid Tumors criteria (version 1.1) (20).

Statistical analysis. Survival curves were drawn according to the Kaplan-Meier method. P-values in the univariate analysis for overall survival (OS) were calculated by the log-rank test. The 95\% confidence interval (CI) was calculated using Greenwood's formula (21). The significance level was set at 5\%. An event was defined as any death in OS calculations, and as any death or progression in progression-free survival calculations, respectively.
Table I. Patient and disease characteristics.

\begin{tabular}{lll}
\hline Parameter & $\begin{array}{l}\text { Number } \\
\text { of cases }\end{array}$ & Frequency $(\%)$ \\
\hline
\end{tabular}

Number of patients $\quad 40$

Number of lesions $\quad 49$

Age at the start of SBRT, years $(n=40)$

Median (range)

$70(51-91)$

KPS at SBRT $(n=49)$

$70 \%$

12.8

$80 \%$

19.1

$90 \%$

68.1

$100 \%$

32

0

Gender $(\mathrm{n}=40)$

Male

Female

Primary tumor $(n=40)$

Esophagus

Lung

20.0

Colorectum

Uterus

Thymus

5.0

Head and neck

5.0

Liver

5.0

Liposarcoma

Primary treatment $(n=40)$

Radical surgery

82.5

Definitive chemoradiation

Chemotherapy

SBRT, stereotactic body radiation therapy; KPS, Karnofsky performance status.

\section{Results}

A total of 40 patients and 49 lesions fulfilled the aforementioned criteria for the present study. Patient and disease characteristics are presented in Table I. The highest KPS score was $90 \%$. Primary tumors in patients recruited in this study were most frequently located in the esophagus (45\%), with the lungs the second most common site (20\%). Surgical resection was the most common primary therapy (83\%).

Target lesion characteristics are presented in Table II. The median interval between primary therapy and OM was 25 months. OM occurred most frequently in the mediastinal LN (61\%). A solitary metastasis comprised the largest proportion of cases (92\%). The median value of the SUV-max was 5.0. Loco-regional metastases of the primary tumor comprised $55 \%$ of OM sites. The median GTV was $18 \mathrm{~cm}^{3}$, and the median PTV was $32.9 \mathrm{~cm}^{3}$ (range, 15.6-166.4 $\mathrm{cm}^{3}$ ).

The outcomes of SBRT are summarized in Table III. The progression of lesions within a radiation field was not observed during the follow-up period. At the last observation, half of all patients had succumbed to cancer. The rate of disease-free 
Table II. Target lesion characteristics $(n=49)$.

\begin{tabular}{|c|c|c|}
\hline Characteristics & $\begin{array}{l}\text { Number } \\
\text { of cases }\end{array}$ & $\begin{array}{c}\text { Frequency } \\
(\%)\end{array}$ \\
\hline \multicolumn{3}{|c|}{$\begin{array}{l}\text { Interval between diagnosis } \\
\text { of primary tumor and } \\
\text { SBRT/per lesion (months) }\end{array}$} \\
\hline Mean & 41 & \\
\hline Median (range) & $25(2-169)$ & \\
\hline \multicolumn{3}{|l|}{ SBRT site } \\
\hline Mediastinum LN & 30 & 61.2 \\
\hline Supraclavicular LN & 7 & 14.3 \\
\hline Chest wall/pleural/rib & 4 & 8.2 \\
\hline Pelvic/Para-aortic LN & 4 & 8.2 \\
\hline Hilar LN & 3 & 6.1 \\
\hline Axilla LN & 1 & 2.0 \\
\hline \multicolumn{3}{|l|}{ Number of treated lesions } \\
\hline 1 & 45 & 91.8 \\
\hline 2 & 3 & 6.1 \\
\hline 3 & 1 & 2.0 \\
\hline \multicolumn{3}{|l|}{ SUV-max by FDG-PET } \\
\hline Median (range) & $5.0(2.3-17.1)$ & \\
\hline \multicolumn{3}{|l|}{ SBRT treatment group } \\
\hline Locoregional & 27 & 55.1 \\
\hline Metastatic & 22 & 44.9 \\
\hline \multicolumn{3}{|l|}{ GTV volume $\left(\mathrm{cm}^{3}\right)$} \\
\hline Mean & 25.0 & \\
\hline Median (range) & $18.0(8.0-120.0)$ & \\
\hline GTV > $60 \mathrm{cc}$ & 3 lesions & \\
\hline
\end{tabular}

SBRT, stereotactic body radiation therapy; LN, lymph node, FDG-PET, 2-(18F)fluro-2-deoxuy-D-glucose-positron emission tomography; GTV, gross tumor volume; SUV-max, maximum standardized uptake value.

patients was $45 \%$; $60 \%$ of cases ended with distant progression (some of these cases were cured by salvage therapy), occurring in the lung, LN, primary tumor site, liver, bone and brain in eight, seven, three, three, two and one cases, respectively.

All SBRT treatments were intended to be curative. As for the disease extent at the onset of SBRT, all 49 lesions were not associated with other lesions. A total of 9 patients underwent prior radiotherapy for the primary tumor. No concomitant systemic therapy was undertaken for all 49 lesions. Two patients received chemotherapy prior to SBRT.

The median follow-up time was 14.0 months (range, 6.8-57.1 months). The median time to distant progression after SBRT was 4.9 months (range, 0.7-34.2 months); the time was computed from a diagnosis of the treated OM. The date of initiating SBRT for OM was calculated as day 0 in survival. OS (Fig. 1) and progression-free survival (PFS; Fig. 2) curves were generated using the Kaplan-Meier method. The median survival time was 22.5 months (95\% CI, 13.3-40.7 months). The 2- and 3-year OS rates were $45.1 \%$ (range, 26.9-61.7\%) and 36.1\% (range, 18.8-53.7\%), respectively. The median PFS time was 11.3 months
Table III. SBRT outcomes.

\begin{tabular}{lcc}
\hline Outcome & $\begin{array}{c}\text { Number } \\
\text { of cases }\end{array}$ & $\begin{array}{c}\text { Frequency } \\
(\%)\end{array}$ \\
\hline Response to SBRT (n=49) & & \\
Complete response & 24 & 49.0 \\
Partial response & 8 & 16.3 \\
Stable disease & 8 & 16.3 \\
Progressive disease (local) & 0 & 0 \\
Distant progression (n=40) & 24 & 60.0 \\
Status at the last observation $(\mathrm{n}=40)$ & & \\
No evidence of disease & 18 & 45.0 \\
Alive with disease & 0 & 0 \\
Cancer-related mortality & 20 & 50.0 \\
Unrelated mortality & 2 & 5.0 \\
\hline
\end{tabular}

SBRT, stereotactic body radiation therapy.

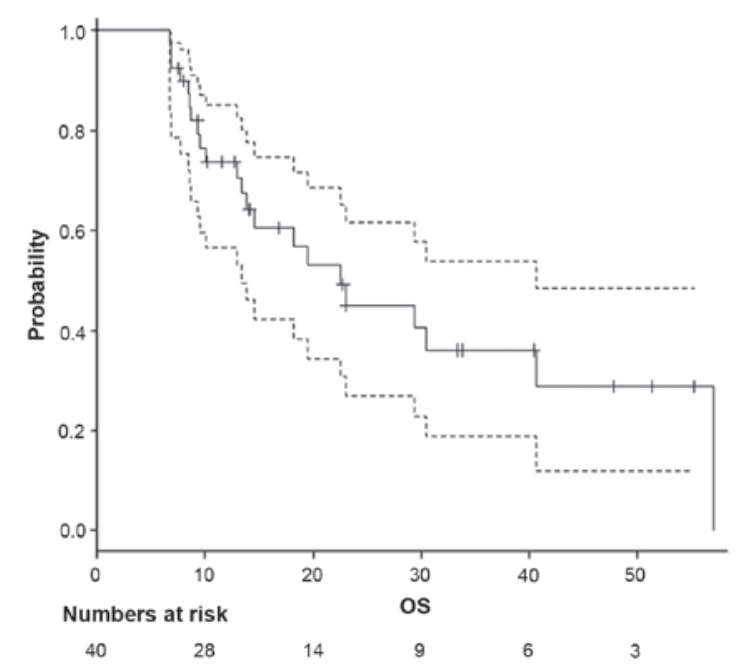

Figure 1. Kaplan-Meier curve of OS. The dashed lines represent the $95 \%$ confidence interval curves. OS, overall survival.

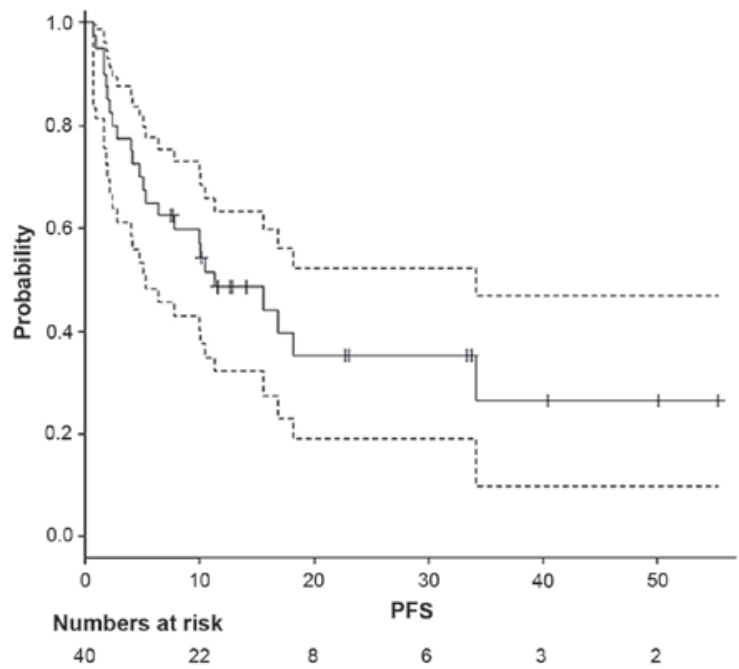

Figure 2. Kaplan-Meier curve of PFS. The dashed lines represent the $95 \%$ confidence interval curves. PFS, progression-free survival. 
Table IV. Univariate analysis of factors that affected OS and PFS.

\begin{tabular}{|c|c|c|c|c|c|c|c|}
\hline \multirow[b]{2}{*}{ Factors } & \multirow[b]{2}{*}{$\mathrm{N}$} & \multicolumn{2}{|c|}{ OS } & \multirow[b]{2}{*}{ P-value } & \multicolumn{2}{|c|}{ PFS } & \multirow[b]{2}{*}{ P-value } \\
\hline & & $\begin{array}{l}\text { Median } \\
\text { (months) }\end{array}$ & $\begin{array}{l}95 \% \mathrm{CI} \\
\text { (months) }\end{array}$ & & $\begin{array}{l}\text { Median } \\
\text { (months) }\end{array}$ & $\begin{array}{l}95 \% \mathrm{CI} \\
\text { (months) }\end{array}$ & \\
\hline \multicolumn{8}{|l|}{ GTV } \\
\hline$>20 \mathrm{~cm}^{3}$ & 18 & 14.5 & $9.6-30.5$ & 0.12 & 7.5 & $2.8-16.8$ & 0.052 \\
\hline$\leq 20 \mathrm{~cm}^{3}$ & 22 & 40.1 & 12.9-NA & & 34.2 & 6.4-NA & \\
\hline \multicolumn{8}{|c|}{$\begin{array}{l}\text { Interval between the } \\
\text { primary therapy and OM (years) }\end{array}$} \\
\hline$\leq 1$ & 7 & 19.5 & 6.8-NA & 0.32 & 10.0 & 2.8-NA & 0.29 \\
\hline$>1$ & 33 & 23.0 & $13.3-\mathrm{NA}$ & & 11.3 & 5.3-NA & \\
\hline$\leq 2$ & 20 & 18.2 & $8.4-30.5$ & 0.041 & 7.7 & $1.9-16.8$ & 0.028 \\
\hline$>2$ & 20 & 29.4 & 13.3-NA & & 34.2 & $6.4-\mathrm{NA}$ & \\
\hline \multicolumn{8}{|l|}{ Primary tumor } \\
\hline Esophagus & 18 & 13.8 & $8.4-23.0$ & 0.026 & 7.7 & $2.8-15.6$ & 0.10 \\
\hline Lung & 8 & 30.5 & 9.6-NA & & 16.8 & 2.2-NA & \\
\hline Others & 14 & NA & 10.1-NA & & NA & 2.4-NA & \\
\hline \multicolumn{8}{|l|}{ SBRT target } \\
\hline Mediastinum & 25 & 23.0 & 12.9-NA & 0.65 & 15.6 & $7.7-34.2$ & 0.55 \\
\hline Others & 15 & 14.5 & 8.5-NA & & 6.4 & $1.7-\mathrm{NA}$ & \\
\hline \multicolumn{8}{|l|}{ Primary treatment } \\
\hline Surgical resection & 30 & 29.4 & 13.3-NA & 0.088 & 10.5 & 5.3-NA & 0.57 \\
\hline Others & 10 & 22.5 & 6.8-NA & & 11.3 & $0.7-\mathrm{NA}$ & \\
\hline
\end{tabular}

P-values calculated via log-rank test. OS, overall survival; PFS, progression-free survival; GTV, gross tumor volume; OM, oligometastasis; SBRT, stereotactic body radiation therapy; NA, not applicable (still alive); CI, confidence interval.

(range, 5.3-34.2 months). The 2- and 3-year PFS rates were $35.4 \%$ (range, $19.0-52.2 \%$ ) and $26.5 \%$ (range, $9.7-47.0 \%$ ), respectively. The median survival time of the 2 patients who received pre-chemotherapy before SBRT was 14.5 and 12.7 months, respectively. Additionally, the median survival time of 1 patient with three OM lesions was 23.0 months.

The results of the univariate analysis of factors that affected OS and PFS are presented in Table IV. A significant difference in both OS and PFS was seen based on the interval between diagnosis and detection of $\mathrm{OM}(<2$ years vs. $>2$ years $(\mathrm{P}=0.041$ and $\mathrm{P}=0.028$, respectively, via log-rank test; Fig. 3 ). A primary tumor located in the esophagus was significantly associated with worse OS compared with lung or other locations $(\mathrm{P}=0.026$; Fig. 4). Patients with OM from esophageal cancer succumbed to further distant metastases $(n=9)$ or local recurrence $(n=3)$ with the exception of 1 patient; patients with OM from lung cancer died of further distant metastases $(n=5)$ and no local recurrence.

For acute radiation toxicities, five events were grade 1 and two events were grade 2 . For subacute and late toxicities, grade 3 radiation enteritis was seen in one case at 0.7 months, grade 4 radiation proctitis in one case at 2.7 months and grade 4 radiation mediastinitis in one case at 9.0 months after SBRT.

\section{Discussion}

In the present study, the median survival time after SBRT for OM was $\sim 2$ years, a period comparable to that observed in previous reports (5), although study participants were not approved for concurrent chemoradiation. As $92 \%$ of patients had a single isolated OM in this study, treatment results may have been relatively positive even without combined chemotherapy. In 2012, Jereczek-Fossa et al (22) reported the outcome of SBRT using $33 \mathrm{~Gy}$ in three fractions for 16 LN cancers from prostate cancer. No regrowth occurred within the irradiated field, while PFS was $>30$ months. In 2014, the same group (18) performed linac-based SBRT for the recurrence of isolated abdominal LN cancers. Various dose fractions such as 6-45 Gy in 1-5 fractions (mean, 24 Gy) were included. The median BED was 120 Gy. For 81 evaluable lesions, a complete response was achieved in $44 \%$ of lesions, a partial response in $26 \%$ and stable disease in $25 \%$. Milano et al (23) reported that the 2-year local control rate was $74 \%$ in non-breast cancer cases. Surgical resection is less likely to be indicated for abdominal LN cancers, while a high local control rate of $70-80 \%$ after SBRT has been reported $(20,21)$. The 49 lesions within the irradiation field had not progressed in any of the cases examined. This indicated that the irradiation dose of 50 Gy in 10 fractions was sufficient. However, new distant metastases developed outside the irradiation field, which were the cause of death in a number of cases.

For patients who showed an interval prior to OM occurrence of $>2$ years, the prognosis was improved compared with those with an interval $<2$ years, as previously reported (4). 


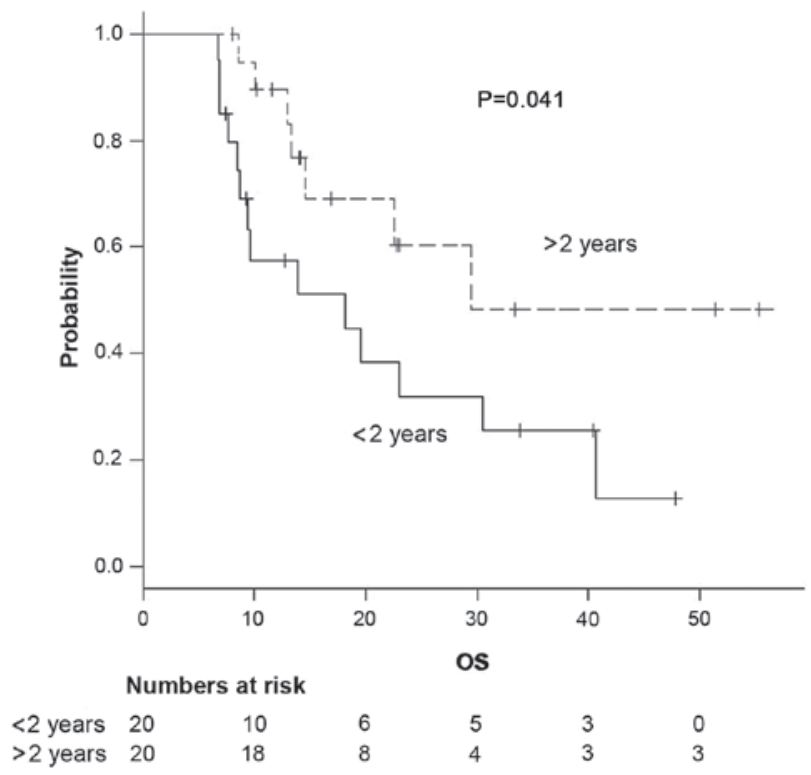

Figure 3. OS curves based on the interval prior to OM. Patients were separated based on an interval before $\mathrm{OM}$ of $<2$ years (solid line) vs. $>2$ years (dashed line) $(\mathrm{P}=0.041)$. OM, oligometastasis; OS, overall survival.

OM from esophageal cancer had a worse prognosis than that from other primary tumors. This is consistent with the fact that esophageal cancer itself has a poor prognosis (23). The site of OM was not a prognostic factor. As most patients had an isolated $\mathrm{OM}$, the difference in prognosis according to the number of OM could not be compared in this study.

Further distant metastases were more likely to occur in patients with OM from esophageal cancer (50\%) and lung cancer $(62.5 \%)$. The difference in survival for each type of cancer could be justified by their differing characteristics.

A grade 4 side effect of radiation therapy was observed in two cases. In both cases, a recurrence outside of the field occurred at the same time as the side effect. A case showing a grade 4 intestinal perforation had uncontrolled diabetes. In a case with an esophageal perforation, a higher radiation-dose region had spread around the trachea, perhaps as it was difficult to increase the dose to the surrounding lungs. Additionally, in this case, the dose was prescribed to cover 95\% of the PTV using VMAT. After this case, the prescription point was positioned on the isocenter at our institution. In 2006, Hoyer et al (24) were the first to report SBRT for a total of 64 metastases for up to three lesions per patient from colorectal cancer, with a 2-year local control rate of 79\%, although serious side effects were reported in several cases. In 2008, Kim et al (25) carried out SBRT of 36-51 Gy in three fractions using a cyberknife on 23 patients with pelvic LN metastases from rectal cancer, and reported that the 4 -year local PFS was $74.3 \%$. A grade 4 rectal perforation occurred in one case with $51 \mathrm{~Gy}$. Casamassima et al (26) reported that only a Radiation Therapy Oncology Group grade 1 side effect occurred after SBRT of 45 Gy in six fractions for abdominal or pelvic LN metastases from prostate cancer. Corvò et al (27) treated 36 patients with SBRT of 35 Gy in five fractions per week. Lesions were confined to the pelvis, hepatic portal section and retroperitoneal space. Moderate to severe acute side effects did not occur. In this study, brachial

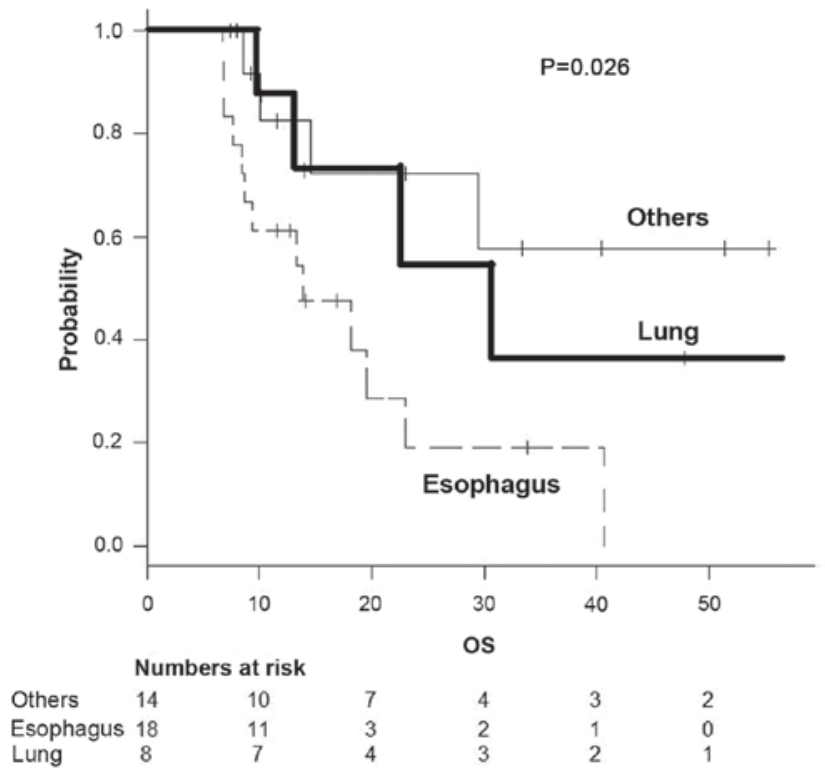

Figure 4. OS curves according to primary tumor site. Patients were separated based on primary tumors situated in the esophagus (dashed line), lung (bold line) or other locations (solid line) $(\mathrm{P}=0.026)$. OS, overall survival.

plexus palsy did not occur in seven lesions for $7,7,8,8,14$, 18 and 34 months, even if 50 Gy of radiation was used in the supraclavicular region. The risk of the occurrence of the palsy may be high, as only 1 patient could be followed for $>2$ years.

Regarding the limitations of this study, first of all, the number of cases investigated was small. In addition, this was a retrospective study in which irradiation sites varied spanning supraclavicular to pelvic regions. OM was proven pathologically in only certain patients. Although a tendency to increase the size and uptake of FDG in PET imaging was confirmed, there may be the possibility of infection or other factors affecting this. Furthermore, the primary tumors studied also varied. Finally, 2 patients that received pre-chemotherapy prior to SBRT and 1 patient with 3 OM lesions were also included.

SBRT of 50 Gy in 10 fractions for OM by various primary tumors was demonstrated to be practical, with good clinical outcomes from the standpoints of local control and frequency of toxic side effects. However, additional studies are required in order to identify patient groups that would receive maximum benefits from this treatment.

\section{Acknowledgements}

The authors thank Miss Alisha Huang (Taipei European School) for the English proofreading.

\section{Funding}

No funding was received.

\section{Availability of data and materials}

The datasets during and/or analyzed during the current study available from the corresponding author on reasonable request. 


\section{Authors' contributions}

HY designed the study, and wrote the initial draft of the manuscript. MO contributed to analysis and interpretation of data, and assisted in the preparation of the manuscript. SA, $\mathrm{OA}$, and $\mathrm{KN}$ contributed to data collection and interpretation, and critically reviewed the manuscript. All authors approved the final version of the manuscript, and agree to be accountable for all aspects of the work in ensuring that questions related to the accuracy or integrity of any part of the work are appropriately investigated and resolved.

\section{Ethics approval and consent to participate}

Informed consent was obtained from all patients prior to the procedures. Ethical approval was granted by the Clinical Research Review Board of the University of Tokyo Hospital.

\section{Patient consent for publication}

Not applicable.

\section{Competing interests}

All authors declare they have no competing interests.

\section{References}

1. Ashworth A, Rodrigues G, Boldt G and Palma D: Is there an oligometastatic state in non-small cell lung cancer? A systematic review of the literature. Lung Cancer 82: 197-203, 2013.

2. Salah S, Tanvetyanon T and Abbasi S: Metastatectomy for extra-cranial extra-adrenal non-small cell lung cancer solitary metastases: Systematic review and analysis of reported cases Lung Cancer 75: 9-14, 2012.

3. https://www.cancer.gov/publications/dictionaries/cancer-terms/def/ oligometastasis

4. Yano T, Haro A, Yoshida T, Morodomi Y, Ito K, Shikada Y, Shoji F, Maruyama R and Maehara Y: Prognostic impact of local treatment against postoperative oligometastases in non-small cell lung cancer. J Surg Oncol 102: 852-855, 2010.

5. Alongi F, Arcangeli S, Filippi AR, Ricardi U and Scorsetti M: Review and uses of stereotactic body radiation therapy for oligometastases. Oncologist 17: 1100-1107, 2012.

6. De Ruysscher D, Wanders R, van Baardwijk A, Dingemans AM, Reymen B, Houben R, Bootsma G, Pitz C, van Eijsden L, Geraedts W, et al: Radical treatment of non-small-cell lung cancer patients with synchronous oligometastases: Long-term results of a prospective phase II trial (Nct01282450). J Thorac Oncol 7: 1547-1555, 2012.

7. Griffioen GH, Toguri D, Dahele M, Warner A, de Haan PF, Rodrigues GB, Slotman BJ, Yaremko BP, Senan S and Palma DA Radical treatment of synchronous oligometastatic non-small cell lung carcinoma (NSCLC): Patient outcomes and prognostic factors. Lung Cancer 82: 95-102, 2013.

8. Tree AC, Khoo VS, Eeles RA, Ahmed M, Dearnaley DP, Hawkins MA, Huddart RA, Nutting CM, Ostler PJ and van As NJ: Stereotactic body radiotherapy for oligometastases. Lancet Oncol 14: e28-e37, 2013.

9. Engels B, Gevaert T, Everaert H, De Coninck P, Sermeus A, Christian N, Storme G, Verellen D and De Ridder M: Phase II study of helical tomotherapy in the multidisciplinary treatment of oligometastatic colorectal cancer. Radiat Oncol 7: 34, 2012.

10. Milano MT, Katz AW, Zhang H and Okunieff P: Oligometastases treated with stereotactic body radiotherapy: Long-term follow-up of prospective study. Int J Radiat Oncol Biol Phys 83: 878-886, 2012.

11. Hasselle MD, Haraf DJ, Rusthoven KE, Golden DW, Salgia R, Villaflor VM, Shah N, Hoffman PC, Chmura SJ, Connell PP, et al: Hypofractionated image-guided radiation therapy for patients with limited volume metastatic non-small cell lung cancer. J Thorac Oncol 7: 379-381, 2012.
12. Choi CW, Cho CK, Yoo SY, Kim MS, Yang KM, Yoo HJ, Seo YS, Kang JK, Lee DH, Lee KH, et al: Image-guided stereotactic body radiation therapy in patients with isolated para-aortic lymph node metastases from uterine cervical and corpus cancer. Int J Radiat Oncol Biol Phys 74: 147-153, 2009.

13. Kim MS, Yoo SY, Cho CK, Yoo HJ, Yang KM, Kang JK, Lee DH, Lee JI, Bang HY, Kim MS and Kang HJ: Stereotactic body radiotherapy for isolated para-aortic lymph node recurrence after curative resection in gastric cancer. J Korean Med Sci 24: 488-492, 2009.

14. Kim MS, Cho CK, Yang KM, Lee DH, Moon SM and Shin YJ: Stereotactic body radiotherapy for isolated paraaortic lymph node recurrence from colorectal cancer. World J Gastroenterol 15: 6091-6095, 2009.

15. Hanna GG and Landau D: Stereotactic body radiotherapy for oligometastatic disease. Clin Oncol (R Coll Radiol) 27: 290-297, 2015.

16. Duan Y, Li J, Zhang Y, Wang W, Sun X, Fan T, Shao Q, Xu M, Guo Y and Shang D: Comparison of primary tumour volumes delineated on four-dimensional computed tomography maximum intensity projection and (18) F-fluorodeoxyglucose positron emission tomography computed tomography images of non-small cell lung cancer. J Med Imaging Radiat Oncol 59: 623-630, 2015.

17. Schag CC, Heinrich RL and Ganz PA: Karnofsky performance status revisited: Reliability, validity, and guidelines. J Clin Oncol 2: 187-193, 1984.

18. Trotti A, Colevas AD, Setser A, Rusch V, Jaques D, Budach V, Langer C, Murphy B, Cumberlin R, Coleman CN and Rubin P: CTCAE v3.0: Development of a comprehensive grading system for the adverse effects of cancer treatment. Semin Radiat Oncol 13: 176-181, 2003.

19. Greene FL, Page DL, Fleming ID, Fritz AG, Balch CM, Haller DG and Morrow M (eds): Esophagus. In: American Joint Committee on Cancer (AJCC) cancer staging manual. 6th edition. Springer, New York, NY, pp167-178, 2002.

20. Eisenhauer EA, Therasse P, Bogaerts J, Schwartz LH, Sargent D, Ford R, Dancey J, Arbuck S, Gwyther S, Mooney M, et al: New response evaluation criteria in solid tumours: Revised RECIST guideline (version 1.1). Eur J Cancer 45: 228-247, 2009.

21. Pokhrel A, Dyba T and Hakulinen T: A greenwood formula for standard error of the age-standardised relative survival ratio. Eur J Cancer 44: 441-447, 2008.

22. Jereczek-Fossa BA, Beltramo G, Fariselli L, Fodor C, Santoro L, Vavassori A, Zerini D, Gherardi F, Ascione C, Bossi-Zanetti I, Mauro R, Bregantin A, Bianchi LC, De Cobelli O and Orecchia R: Robotic image-guided stereotactic radiotherapy, for isolated recurrent primary, lymph node or metastatic prostate cancer. Int J Radiat Oncol Biol Phys 82: 889-897, 2012.

23. Milano MT, Katz AW, Schell MC, Philip A and Okunieff P: Descriptive analysis of oligometastatic lesions treated with curative-intent stereotactic body radiotherapy. Int J Radiat Oncol Biol Phys 72: 1516-1522, 2008.

24. Hoyer M, Roed H, Traberg Hansen A, Ohluis L, Petersen J, Nellemann H, Kiil Berthelsen A, Grau C, Aage Engelholm S and Von der Maase H: Phase II study on stereotactic body radiotherapy of colorectal metastases. Acta Oncol 45: 823-830, 2006.

25. Kim MS, Choi C, Yoo S, Cho C, Seo Y, Ji Y, Lee D, Hwang D, Moon S, Kim MS and Kang H: Stereotactic body radiation therapy in patients with pelvic recurrence from rectal carcinoma. Jpn J Clin Oncol 38: 695-700, 2008.

26. Casamassima F, Masi L, Menichelli C, Bonucci I, Casamassima E, Lazzeri M, Gulisano M and Aterini S: Efficacy of eradicative radiotherapy for limited nodal metastases detected with choline PET scan in prostate cancer patients. Tumori 97: 49-55, 2011.

27. Corvò R, Lamanna G, Vagge S, Belgioia L, Bosetti D, Aloi D, Timon $\mathrm{G}$ and Bacigalupo A: Once-weekly stereotactic radiotherapy for patients with oligometastases: Compliance and preliminary efficacy. Tumori 99: 159-163, 2013.

This work is licensed under a Creative Commons Attribution-NonCommercial-NoDerivatives 4.0 International (CC BY-NC-ND 4.0) License. 